\title{
A 'new normal' following COVID-19 and the economic crisis: Using systems thinking to identify challenges and opportunities in disability, telework, and rehabilitation
}

\author{
Tiago S. Jesus ${ }^{\mathrm{a}, \mathrm{b}, *}$, Michel D. Landry ${ }^{\mathrm{c}, \mathrm{d}}$ and Karen Jacobs ${ }^{\mathrm{b}}$ \\ ${ }^{\mathrm{a}}$ Global Health and Tropical Medicine and WHO Collaborating Center on Health Workforce Policy and Planning, \\ Institute of Hygiene and Tropical Medicine, NOVA University of Lisbon, Lisbon, Portugal \\ ${ }^{\mathrm{b}}$ Department of Occupational Therapy, College of Health and Rehabilitation Sciences, Sargent College, Boston \\ University, MA, USA \\ ${ }^{\mathrm{c}}$ School of Medicine, Duke University, Durham, NC, USA \\ ${ }^{\mathrm{d}}$ Duke Global Health Institute, Duke University, Durham, NC, USA
}

Received 12 June 2020

Accepted 27 July 2020

\begin{abstract}
.
BACKGROUND: The novel coronavirus (COVID-19) that emerged in late 2019, and later become a global pandemic, has unleashed an almost unprecedented global public health and economic crisis.

OBJECTIVE: In this perspective, we examine the effects of COVID-19 and identify a likely 'new normal' in terms of challenges and opportunities within the fields of disability, telework, and rehabilitation.

METHODS: We use a systems thinking lens informed by recent empirical evidence and peer-reviewed qualitative accounts regarding the pandemic to identify emerging challenges, and pinpoint opportunities related to health and changing employment infrastructure of people with disabilities and rehabilitation professionals.

RESULTS: From our interpretation, the key leverage points or opportunities include: (1) developing disability-inclusive public health responses and emergency preparedness; (2) enabling employment and telework opportunities for people with disabilities; (3) addressing the new requirements in rehabilitation service provision, including participating as essential team members in the care of people with infectious diseases such as COVID-19; (4) embracing the added emphasis on, and capacity for, telehealth; and (5) developing greater resilience, distance learning, and employability among the rehabilitation workforce.

CONCLUSIONS: The COVID-19 pandemic has become increasingly challenging to the lives of people with disabilities and rehabilitation professionals; however, key challenges can be minimized and opportunities can be capitalized upon in order to ‘build back better' after COVID-19.
\end{abstract}

Keywords: People with disabilities, novel coronavirus, COVID-19, rehabilitation services, telehealth

*Address for correspondence: Tiago S. Jesus, Rua da Junqueira, 100 1349-008 Lisbon, Portugal. Tel.: +351 213652 600; Fax: +351 213632 105; E-mail: jesus-ts@outlook.com.

\section{Introduction}

The novel coronavirus (COVID-19) emerged in late December 2019. Given the highly infectious nature of the SARS-CoV-2 virus, COVID-19 quickly 
became an infectious-disease outbreak of rare global proportions. On January 13, 2020, there were a total of 42 positive cases worldwide, but within four months, the number of positive global cases increased to 4,179479 representing a daily average increase of 34,257 positive cases [1]. Although it also appears that, at the time of this publication, an effective vaccine may require some time to develop and distribute, economies around the world have begun to re-open and allow closer interactions. This re-opening of economies and society are occurring while the global rates continue to increase and while there is likely a second of wave of new positive cases and case fatalities. History will judge the effectiveness of the global communities move towards reopening at a time when the total number of affected individuals reaches the 6 million thresholds.

The impact of the COVID-19 pandemic has not been equally distributed across all populations. For instance, COVID-19 has had an important impact on vulnerable subpopulations, including the older persons and those with previous health conditions [1,2]. More specifically, people with disabilities have been disproportionally affected [3, 4] along with other minority groups, including but not limited to, African American men in the United States [5]. Simultaneous to the global public health crisis, an economic crisis also unleashed important consequences on countries of all income levels. As a public health measure towards containing the COVID-19 outbreak, health and government authorities across all countries have implemented strategies such as social distancing and lockdown measures with the goal of reducing the spread, and flattening the curve of new positive cases. These public health instruments provoked an abrupt economic contraction, and resulted in unemployment in many sectors and reduced income for many people. It would be an understatement to suggest that work patterns have changed since the outbreak, and the questions is whether these economic changes will remain, or whether the workforce will return to previous work structures. For some groups, such as people with disabilities, they become much more vulnerable in scenarios when level of income is reduced, and when work changes or when unemployment results [6-11]. On the other hand, given reasonable accommodations (e.g. in accordance with the American with Disabilities Act or other applicable legislative components), people with disabilities can successfully and meaningfully engage in telework because technology can act as mediating factor [12, 13]. For persons with disabilities, a myriad of health and employment-related challenges and opportunities have arisen from the pandemic.

Rehabilitation services and providers, including but not limited to, occupational and physical therapists, have also been challenged by the pandemic. Paradoxically, while need in some rehabilitation sectors have been highlighted (such as in patient respiratory physical therapy), other sectors have experienced a lowering of demand, particularly for outpatient or home-based rehabilitation. The differential impact of sub-sectors of rehabilitation industry has highlighted the need for rapidly developing and applying contingency plans to mediate these economic and practice pattern effects $[14,15]$.

In short, COVID-19 poses numerous challenges for people with disabilities, their advocates, disability-inclusive policy and public health decisionmakers, and for rehabilitation stakeholders alike. However, opportunities may arise from these challenges. In this paper, we use a systems thinking (ST) perspective to explore and elaborate on current challenges, and offer suggestions on where opportunities can be seized in order to develop a 'new normal' in a post-COVID-19 pandemic era.

\subsection{Theoretical lens and paper structure}

In this paper, we applied a systems thinking (ST) lens to explore and elaborate on a perspective paper about the challenges and opportunities for the disability and rehabilitation fields during the COVID-19 pandemic $[16,17]$.

\subsubsection{Systems thinking (ST)}

The ST lens has been increasingly adopted to identify and solve complex challenges in health systems [16-18], global public health [19, 20], health policy [21, 22], rehabilitation [23-25], and disability fields [26-28]. The ST approach encourages the recognition of response patterns beyond isolated events, and emphasizes the areas of the system (i.e. leverage points) from which small changes can yield considerable ramifications, either positive (i.e. opportunities to be seized) or negative (i.e. challenges to be addressed, prevented or mitigated).

A ST lens also posit that components of a systems, e.g. their actors, structures, processes, networks, are: (1) highly interconnected, (2) dynamic in their responses, (3) self-organizing in nature, yet (4) sensitive to significant external changes originating a cascade of responses and effects $[16,17,20]$. The COVID-19 pandemic is a significant, disrupting, 
external event likely affecting every societal system, their inner equilibrium, and their outer relations. The current pandemic, entailing a public, clinical, and economic crisis, will likely bring with it complex challenges and a cascade of responses until a 'new normal', i.e. a new system's equilibrium is achieved within and across societal systems.

In this paper, we follow the standpoint that once identified, leverage points can be used to influence effective change. Also, we follow the standpoint that time of crises provide opportunities for transformational improvements beyond incremental processes that are more usual in 'regular' or nonpandemic times [29].

\subsubsection{Paper type and structure}

This article refers to the authors' perspective based on a ST lens. ST was used a guide to better understand the challenges and opportunities for a 'new normal' following the COVID-19 pandemic. To inform our perspective, we reviewed recent empirical evidence related to the pandemic, with an emphasis on health and work-related issues. Such evidence was found through a snowballing search process initiated with a PubMed, Scopus, and CINHAL database searches, conducted at the end of April 2020, combining key terms related to: rehabilitation, people with disabilities, health, employment, and COVID-19.

We included peer-reviewed papers that were empirical or original studies, but also qualitative accounts (e.g. perspectives, commentaries, case reports) published in peer-reviewed scientific journals, and finally any relevant statements, recommendations, or position papers from official public health authorities or representative associations (e.g. of rehabilitation health workers). The included material needed to highlight disability or rehabilitation-related consequences or responses to the COVID-19 pandemic or resultant events (e.g. economic crisis; change in rehabilitation service demand). In the absence of sources focused specifically on COVID-19, we included applicable evidence from before the pandemic (e.g. on the employment of people with disabilities versus non-disabled counterparts) as a material to inform our perspectives. Finally, this iterative search and synthesis process was deemed completed according to a qualitative "saturation' principle, i.e. when newly found information added no different perspectives or no more solid evidence to the same perspective [30, 31]. Finally, a qualitative thematic analysis and synthesis was iteratively developed to build and refine the key leverage points identified, below presented in the form of challenges and opportunities for the 'new normal' after the COVID-19 pandemic [30].

\subsection{Challenges and opportunities}

Figure 1 provides a visual display of leverage points for a more disability-inclusive society and a value-based rehabilitation (i.e. cost-effective, accessible, equitable as well as person- and populationcentred) that may arise from the COVID-19 pandemic. Within each of the following sections, we depicted each of the main leverage points, including intricate challenges to be addressed and key opportunities. Overall, we suggest that there is important disequilibrium, meaning that COVID-19 has exerted a significant impact on the disability and rehabilitation sectors). However, we also signal that the levers listed below can help to create an equilibrium and mediate the devastative effects of COVID- 19 .

\subsubsection{Leaver \#1: developing disability-inclusive public health responses and emergency preparedness}

From a health standpoint, people with disabilities are especially vulnerable to the COVID-19 and require disability-inclusive public health responses $[3,32]$. As a group, people with disabilities face higher risks of contracting the COVID-19 [3, 4]. Due to the nature of the challenges that people with disabilities may experience, they may have greater difficulties understanding or otherwise complying with physical distancing and other prevention measures (e.g. thorough handwashing, wearing a mask). Furthermore, people with visual or sensory processing impairments may need to rely on tactile sensation more often than counterparts, making public health recommendations not readily appropriate for persons with disabilities. Finally, due to societal responses, many people with disabilities are institutionalized and hence exposed to physical contacting risks.

Additionally, if and once infected, people with disabilities also face higher risks of more severe consequences. People with disabilities often have higher rates of chronic or secondary conditions [33-36], and given that COVID-19 exacerbates existing health conditions, particularly those related to respiratory function, immune system function, heart disease or diabetes [3], a person with disabilities may experience other severe effects. Across high, middle, and low-income countries, people with disabilities also face disparities in access to needed healthcare 


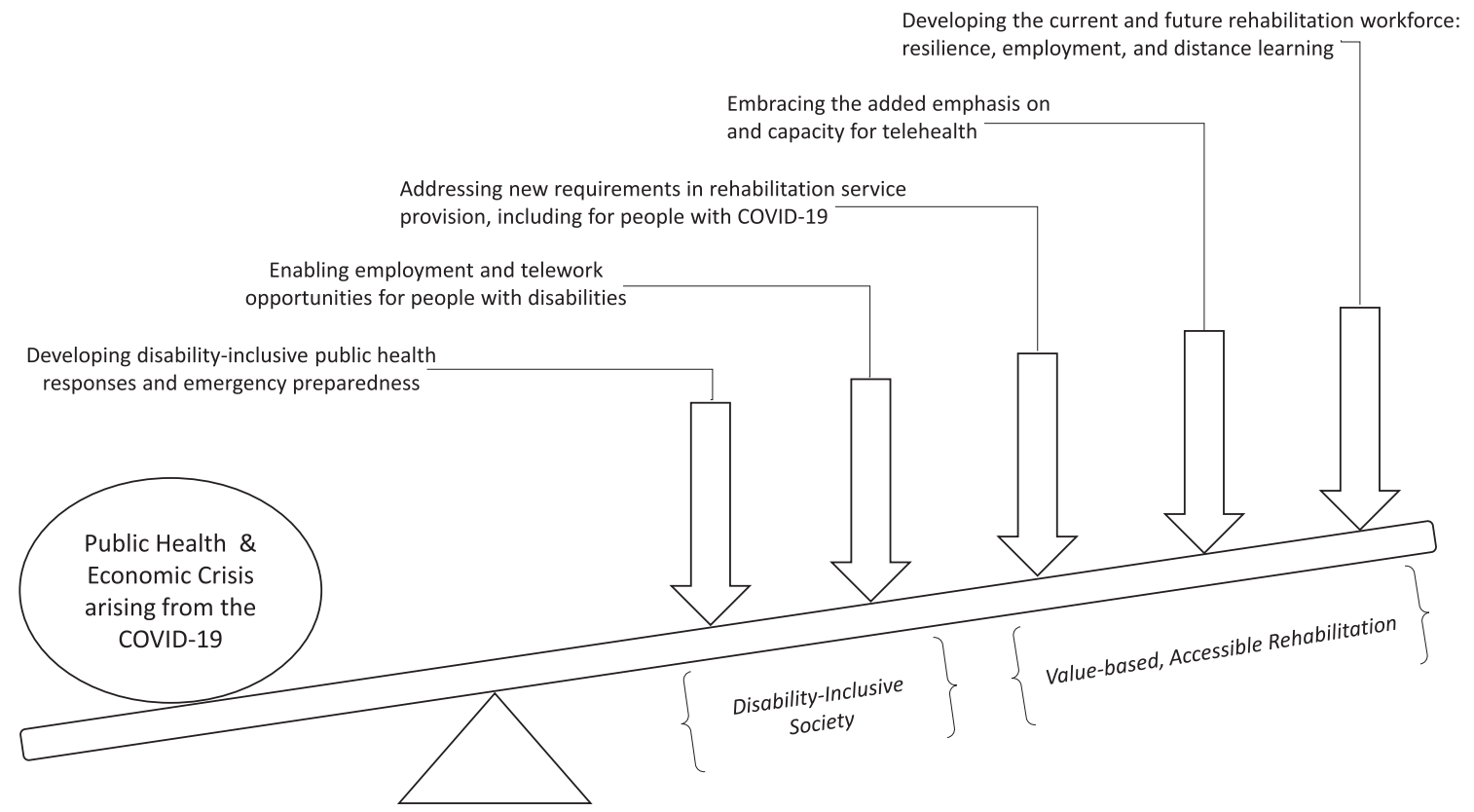

Fig. 1. Visual display of leverage points.

services [37-40]. This also may apply to accessing healthcare for COVID-19. People with disabilities may often rely on social support or caregiving assistance, including for accessing healthcare, while such an assistance may not be as much available under lockdown restrictions [3].

In this context of special vulnerability, worldwide public health authorities might be aware of and act on each of the added risks for people with disabilities. For instance, public health authorities might promote the development of disability-inclusive public health responses now, as well as better prepare for similar emergencies in the future. For now, all COVID-19 preventive communication measure should be disseminated in plain language and across accessible formats, through mass and digital media channels [4]. Also, people with disabilities who have special vulnerabilities (e.g. institutionalized, with chronic conditions, poorest, older, from ethnic minorities, refugees, at home without assistance) might be a target for specific preventive and protection measures.

For the future, people with disabilities will need to be engaged in the formulation of policy and public health responses, including preparedness for any similar public health and economic crises that may severely and disproportionately affect them. This ideal of integrating persons with disabilities into all societal facets and decisions that affect their life isn't new [41-43], even for the scope of public health activities, including planning, surveillance, programming, education, and evaluation [44]. However, the COVID-19 pandemic, and the 'new normal' that likely comes thereafter, might provide a refreshed opportunity to engage people with disabilities in broader public health policy and planning as well as in the emergency preparedness activities. Such level of preparedness can help mitigate the negative, disproportional effects for people with disabilities of a potential second wave of the COVID-19 pandemic or of any other infectious disease outbreak that may arise.

\subsubsection{Leaver \#2: enabling employment and telework opportunities for people with disabilities}

Employment: At the employment and economic level, challenges and opportunities for people with disabilities and inclusive development have arisen from pandemic. Typically, people with disabilities are employed at significantly lower rates than nondisabled counterparts, across countries of varying income level $[6-8,11,36]$. Even though a systematic review found a myriad of primary benefits for employers that hire people with disabilities [45], many people with disabilities continue to face challenges in finding and securing employment $[7,46]$. Social and cultural stereotypes perpetuate employment disparities, for instance, a recent study in the 
United States found that the states with higher disability prejudice scores had lower disability employment rates [6]. With the global COVID-19 pandemic and its economic challenges, one can anticipate that people with disabilities will likely face higher unemployment rates, especially if in the absence of a disability-inclusive development planning at the community and government level [47].

On multiple levels, lack of employment opportunities can be detrimental to people with disabilities. Meaningful employment can benefit people with disabilities in terms of improved quality of life, selfconfidence, social network, sense of community, and obviously income [45]. Also, in countries in which health insurance follows employment status, if people with disabilities are under or unemployed, they face higher risks of being uninsured, and having added difficulties accessing healthcare [48]. In the United States, after the Affordable Care Act, people with disabilities living in Medicaid expansion states were significantly more likely to be employed compared with those in non-expansion states [49]. This expansion helped people with disabilities to increase a proportion of their earnings, which impacted their standard of living in poverty to maintain Medicaid eligibility [49]. All accounted, employment is a meaningful occupation and valuable in itself, but also can protect people from having poor health and well-being, poor finances, and poor access to healthcare when they need. As a challenge, one can state that the global and local development plans (e.g. for the returning of employment and economic growth) need to account for the specific needs of people with disabilities and the importance of maximizing employment in this vulnerable population [32].

Telework: In turn, opportunities may arise for people with disabilities with regards to telework (i.e. the practice of working from home, using information and communication technology (ICT) such as email, telephone and communication or videoconferencing platforms). Since the 1990s, telework has been promoted as a viable and reasonable workplace accommodation for people with disabilities [13]. Yet, the prevalence of telework among people with disabilities did not increase at the same pace as the general population, despite the potential human right benefits [12]. It was reported that people with disabilities telework more often when they have higher educational levels and are categorized as in "white-collar", knowledge-based jobs [12]. During COVID-19 and resultant lockdowns, telework is becoming commonplace, especially with knowledge-based jobs. If the trend is prolonged and becomes part of the 'new normal' after the pandemic, people with disabilities might well benefit from an added emphasis on telework. By developing the needed reasonable accommodations and the structural conditions for people with disabilities to telework, one would be seizing on the opportunity which has emerged out of this surge of necessity. If properly supported, telework can level the playing field in terms of employment opportunities for people with disabilities $[12,13]$.

\subsubsection{Leaver \#3: addressing new requirements in rehabilitation service provision, including for people with COVID-19}

Rehabilitation services have been challenged by the pandemic. Within a short period of time, an increasing number of papers have been published which prepare the rehabilitation community for the organization and delivery of services during the COVID-19 outbreak [14, 50-52]. Challenges have been many, in addition to implementing measures for preventing the COVID-19 dissemination through patients and staff alike. Inpatient rehabilitation services have been pressured to admit patients from acute wards to release capacity for treating COVID19 patients, sometimes with total conversion of rehabilitation-designed beds, wards and even hospitals in the places most hardly hit by the COVID-19, such as Italy $[14,50]$.

In turn, a competitive demand has risen for the provision of respiratory rehabilitation to COVID-19 patients. This has been deemed an important essential component of intervention for many hospitalized COVID-19 patients [53], either for symptom relief or for addressing the pulmonary and respiratory complications, typical of debilitating respiratory-track infectious diseases [53, 54]. Rehabilitation is also important for the critical illness and impairments that may follow COVID-19, including as a result of immobility [54, 55]. For instance, post-intensive care syndrome may come as a result for adults that survive a stay in the intensive care unit, but which experience new or worsening physical disability, mental health problems, cognitive impairment, or occupational disengagement; all of which might be addressed by rehabilitation practitioners [56-58]. Overall, rehabilitation providers can have a vital role for the health system's capacity to move COVID-19 patients on from acute sites to eventual discharge to the community, while reducing any resultant disability [55]. 
Finally, also for lockdown reasons, the provision of outpatient, home-based, community-based, and school-based rehabilitation services has been reduced - often dramatically. Many of those services went viable only through telehealth options, which have been made available for the applicable situations. While this is a challenge thus far, it raises an opportunity for the future - as addressed in the following section.

\subsubsection{Leaver \#4: embracing the added emphasis on and capacity for telehealth}

Telehealth is a general term which includes telerehabilitation in particular as a service delivery model that like telework, uses information and communication technology to deliver health- and rehabilitation-related services when the client is at a distance from the practitioner $[59,60]$. Out of necessity, provision of many types of rehabilitation care, including exercise, support, coaching, or advice, have been moved to a telehealth form of delivery. One has observed a proliferation of recommendations for the use these telerehabilitation options, especially now in the era of COVID-19 and physical distancing measures $[14,15,55]$.

In spite of this recent increase in demand, telehealth is not new. Evidence on the effectiveness and comparative effectiveness is available for many health conditions [61-64]. The use of telehealth provides increased access, equity, and outreach for rehabilitation services, including for people in rural or remote communities of either high- or low-income nations [65-70]. This new increase in demand creates an unprecedented opportunity to scale up the practitioners' habits and capabilities for the use of this service delivery form, as well as scale up the system's capacity (e.g. development of regulatory and reimbursement mechanisms) for the provision of telerehabilitation. Indeed, greater advocacy for telehealth or telerehabilitation services and their reimbursement is now taking place [59, 71]. If the opportunity is taken, this can be one upsides for the 'new normal' after the pandemic.

Telerehabilitation can be key for the supply of the rehabilitation needs of outpatient, home, schoolbased or community-based patients which can be largely unmet otherwise. Also, this means can be used with COVID-19 patients who need to be isolated in hospitals or at home [15, 72]. In addition to immobility, isolation leads to activity and participation restriction, which can cause physical and psychological decline. For example, a recent systematic review with meta-analysis found there was a marked trend for isolated patients to exhibit higher levels of depression [73]. Loneliness, social disconnection and lack of engagement into meaningful activities can strike in people social isolation and especially in the older persons who are likely to be further confined during the pandemic of COVID-19 [72, 74, 75]. Rehabilitation professionals should play a large preventive and rehabilitation role on avoiding a secondary 'epidemic' of loneliness, inactivity, poor mental health, and functional decline, especially in the older persons.

\subsubsection{Leaver \#5: developing the current and future rehabilitation workforce: resilience, employment, and distance learning}

Rehabilitation personnel need to rapidly and readily acquire knowledge on guidelines and recommendations for how to manage and deliver services in the context of the COVID-19 outbreak [53, 76]. They may need to take prioritization, clinical reasoning decisions for which patients, under which circumstances, should rehabilitative care be maintained or postponed, given the competing demands, guidelines issued, resources constrains, and different type of risks involved for staff and patients alike (e.g. contracting the COVID-19 versus impairments aggravation, especially the frail elderly) [58, 76]. Many rehabilitation professionals need to develop, within a short period of time, the knowledge and skills to deliver care through telehealth technology, with quality and safety requirements and according to a myriad of applicable regulations and reimbursements practices. The timing pressure can be challenging. Finally, acute demand for treating COVID-19, especially for respiratory therapists, can be daunting [58]

On the one hand, these abrupt changes can create tremendous strain for the response of the rehabilitation workers as it does, in different ways, for the myriad of health workers too. Healthcare systems and organizations must prepare themselves to prevent, address or mitigate issues of strain, exhaustion, demoralization or burnout of health and rehabilitation care workers at the frontline of the pandemic battle [77, 78]. On the other hand, rehabilitation professionals that work in outpatient, home-based, or other services that have had restricted provision or slip of demand may face the threat of unemployment or underemployment. This has created a paradox resulting from the COVID-19 events, because some rehabilitation providers such as those who provide respiratory care has witnessed an alltime increased demand for their services, while the 
community-based providers have been significantly affected by social distancing measures. This then uncover the vast diversity in the sectors in which rehabilitation providers practice. The effects of economic crises in health workers is a policy concern; and scientific area of study for the health workers in general [79] but not for rehabilitation workers in particular [80]. The exact effect of this economic crisis, which is originated by a public health crisis, will be challenging to understand given apparent the lack of evidence. However, this crisis is an opportunity to develop rehabilitation workforce studies in an economic crisis' context. That could help prepare and execute any preventive or mitigating policy responses when another crisis hit.

On the very upper side, the new roles of rehabilitation professionals with COVID-19 patients can create a greater awareness across stakeholders about the role of rehabilitation professionals and their care for people with infections conditions - as a non-traditional, but increasingly needed scope of practice [54]. It can also add to the awareness and capabilities of the rehabilitation workforce about the possibilities that telehealth technology offers to the delivery of remote care, which can then be prolonged for particular uses (e.g. for underserved patients in rural or remote areas of either higher or lower income locations).

Finally, the upcoming rehabilitation workforce (i.e. those in educational programs, clinical education) as well as their educators are now facing the challenge of moving educational, training, and evaluation activities mostly or fully online, i.e. distance learning. Like in telerehabilitation, these forms of education and training already existed, but soon became the mainstream for this special period of time. The capacity and capabilities that were added, however, likely can flourish for the period after advent of the COVID-19 crisis.

\section{Limitations}

This paper has some limitations. First, the paper refers to an authors' perspective; although the literature was instrumental to build and refine the perspectives provided (e.g. on the key leverage points identified), one cannot understand the information provided in these leverage points as a systematic map or review of the literature. Second, the challenges and opportunities depicted are not intended to be exhaustive, even though they can provide a systemic view, embracing health and employment issues as whole, which arise from a public health and economic crisis. Third, although strategic developments are recommended on each of key leavers identified, we do not suggest (i.e. prescribe) more specific actions to be taken. While this turns the points less actionable, it is a purposive option. The option is aligned with the ST theory and the focus on responses patterns rather than discrete responses or events. Also, ST theory posits that systems are self-organizing in nature, and that actions would need to be context-specific (e.g. adapted to the local 'complex adaptive systems [81-84]), hence more specific recommendations for action hardly could be generalizable - and especially so for a worldwide perspective. Finally, we understand that the prescription of more specific action from the perspective of the authors could stifle innovation and, on the other hand, recognizes that multiple stakeholders have a key role in operationalization, in addition to debating or challenging the strategic leavers identified. Relatedly, a last limitation is that a set of layers, challenges, and opportunities provided are not necessarily exhaustive or closed, and subject to evolution according to stakeholders' perspectives (e.g. beneficiaries) as well as subject to dynamic and partly unpredictable systems' responses to the COVID-19 pandemic.

\section{Conclusion}

The COVID-19 experience this far has created great challenges and new opportunities for the short, middle and longer term. Using the ST approach, this perspective paper depicts key leverage points for the advancement of the disability and rehabilitation fields. These leverage points, operationalized into a set of challenges and opportunities, were organized in terms of: developing disability-inclusive public health responses and emergency preparedness, enabling employment and telework opportunities for people with disabilities, addressing the new requirements in rehabilitation service provision - including in the care of people with COVID-19, embracing the added emphasis on and capacity for telerehabilitation - including for addressing loneliness, and developing the rehabilitation workforce, the current and the future, in terms of resilience, employment, work patterns, and distance learning.

Overcoming these challenges and seizing the opportunities will require diligence, creativity, advocacy, innovative thinking, planning, collaborative execution and advocacy among people with 
disability, their representatives, and rehabilitation stakeholders alike. Challenges and opportunities arising from the pandemic need to be identified and addressed in a systemic and timely manner. If successful, we can move towards a transformed society with improved capacity and capabilities for increasing the health, employment, equity, and quality of life for people with disabilities, broadly a more disability-inclusive society, and a value-based, accessible rehabilitation. To achieve anything less would be a lost opportunity to 'build back better.'

\section{Conflict of interest}

None to report.

\section{References}

[1] Liu K, Chen Y, Lin R, Han K. Clinical features of COVID-19 in elderly patients: A comparison with young and middleaged patients. The Journal of infection. 2020.

[2] Rothan HA, Byrareddy SN. The epidemiology and pathogenesis of coronavirus disease (COVID-19) outbreak. Journal of autoimmunity. 2020;109:102433.

[3] World Health Organization. Disability considerations during the COVID-19 outbreak. Geneva; 2020.

[4] Armitage R, Nellums LB. The COVID-19 response must be disability inclusive. The Lancet Public health. 2020.

[5] NBC News. African Americans may be dying from COVID19 at a higher rate. Better data is essential, experts say. 2020.

[6] Friedman C. The relationship between disability prejudice and disability employment rates. Work (Reading, Mass). 2020;65:591-8.

[7] Ohl A, Grice Sheff M, Small S, Nguyen J, Paskor K, Zanjirian A. Predictors of employment status among adults with Autism Spectrum Disorder. Work (Reading, Mass). 2017;56(2):345-55.

[8] Kumin L, Schoenbrodt L. Employment in Adults with Down Syndrome in the United States: Results from a National Survey. Journal of applied research in intellectual disabilities : JARID. 2016;29(4):330-45.

[9] Donelly M, Gordon S, Bowling A. Income and employment equity of graduates with and without disabilities. Work (Reading, Mass). 2020;65(3):547-61.

[10] Brucker DL, Houtenville AJ. People with disabilities in the United States. Archives of physical medicine and rehabilitation. 2015;96(5):771-4.

[11] Banks LM, Kuper H, Polack S. Poverty and disability in low- and middle-income countries: A systematic review. PloS one. 2017;12(12):e0189996.

[12] Linden M, Milchus K. Teleworkers with disabilities: characteristics and accommodation use. Work (Reading, Mass). 2014;47(4):473-83.

[13] Moon NW, Linden MA, Bricout JC, Baker PM. Telework rationale and implementation for people with disabilities: considerations for employer policymaking. Work (Reading, Mass). 2014;48(1):105-15.
[14] Boldrini P, Bernetti A, Fiore P. Impact of COVID-19 outbreak on rehabilitation services and Physical and Rehabilitation Medicine (PRM) physicians' activities in Italy. An official document of the Italian PRM Society (SIMFER). European journal of physical and rehabilitation medicine. 2020.

[15] Mukaino M, Tatemoto T, Kumazawa N, Tanabe S, Kato M, Saitoh E, et al. Staying active in isolation: Telerehabilitation for individuals with the SARS-CoV-2 infection. American Journal of Physical Medicine \& Rehabilitation. 2020.

[16] Alliance for Health Policy and Systems Research \& World Health Organization. Systems Thinking for Health Systems Strengthening. Geneva; 2009.

[17] Peters DH. The application of systems thinking in health: why use systems thinking? Health Research Policy and Systems. 2014;12(1):51.

[18] Khan S, Vandermorris A, Shepherd J, Begun JW, Lanham HJ, Uhl-Bien M, et al. Embracing uncertainty, managing complexity: applying complexity thinking principles to transformation efforts in healthcare systems. BMC Health Services Research. 2018;18(1):192.

[19] Paxton A, Frost LJ. Using Systems Thinking to train future leaders in global health. Global Public Health. 2018;13(9):1287-95.

[20] Carey G, Malbon E, Carey N, Joyce A, Crammond B, Carey A. Systems science and systems thinking for public health: a systematic review of the field. BMJ Open. 2015;5(12):e009002.

[21] Williams JC. A systems thinking approach to analysis of the Patient Protection and Affordable Care Act. Journal of Public Health Management and Practice: JPHMP. 2015;21(1):6-11.

[22] Achoki T, Lesego A. The imperative for systems thinking to promote access to medicines, efficient delivery, and cost-effectiveness when implementing health financing reforms: a qualitative study. International Journal for Equity in Health. 2017;16(1):53.

[23] Brown CA. The application of complex adaptive systems theory to clinical practice in rehabilitation. Disability and Rehabilitation. 2006;28(9):587-93.

[24] Wallden M. But we're infinitely more complex than a car: A systems approach to health \& performance. Journal of Bodywork and Movement Therapies. 2015;19(4):697-711.

[25] Morris JH, Bernhardsson S, Bird ML, Connell L, Lynch E, Jarvis K, et al. Implementation in rehabilitation: a roadmap for practitioners and researchers. Disability and Rehabilitation. 2019:1-10.

[26] MacLachlan M, McVeigh J, Cooke M, Ferri D, Holloway $\mathrm{C}$, Austin V, et al. Intersections Between Systems Thinking and Market Shaping for Assistive Technology: The SMART (Systems-Market for Assistive and Related Technologies) Thinking Matrix. International Journal of Environmental Research and Public Health. 2018;15(12).

[27] Layton N, Bell D, Buning ME, Chen SC, Contepomi S, Delgado Ramos V, et al. Opening the GATE: systems thinking from the global assistive technology alliance. Disability and Rehabilitation Assistive Technology. 2020:1-7.

[28] Hamdani Y, Jetha A, Norman C. Systems thinking perspectives applied to healthcare transition for youth with disabilities: a paradigm shift for practice, Policy and Research. Child: Care, Health and Development. 2011;37(6):806-14.

[29] Smith K, Ostinelli E, Cipriani A. Covid-19 and mental health: a transformational opportunity to apply an evidence-based approach to clinical practice and research. Evidence-based Mental Health. 2020;23(2):45-6. 
[30] Mays N, Pope, Popay J. Systematically Reviewing Qualitative and Quantitative Evidence to Inform Management and Policy-Making in the Health Field J Health Serv Res Policy. 2005;10 Suppl 1:6-20.

[31] Saunders B, Sim J, Kingstone T, Baker S, Waterfield J, Bartlam B, et al. Saturation in qualitative research: exploring its conceptualization and operationalization. Quality \& Quantity. 2018;52(4):1893-907.

[32] United Nations. A UN framework for the immediate socioeconomic response to COVID-19. 2020.

[33] Rimmer JH, Chen MD, Hsieh K. A conceptual model for identifying, preventing, and managing secondary conditions in people with disabilities. Physical Therapy. 2011;91(12):1728-39.

[34] Moharic M. Research on prevalence of secondary conditions in individuals with disabilities: an overview. International Journal of Rehabilitation Research Internationale Zeitschrift fur Rehabilitationsforschung Revue internationale de recherches de readaptation. 2017;40(4):297-302.

[35] Reichard A, Stolzle H, Fox MH. Health disparities among adults with physical disabilities or cognitive limitations compared to individuals with no disabilities in the United States. Disability and Health Journal. 2011;4(2):59-67.

[36] Gudlavalleti MV, John N, Allagh K, Sagar J, Kamalakannan S, Ramachandra SS. Access to health care and employment status of people with disabilities in South India, the SIDE (South India Disability Evidence) study. BMC Public Health. 2014;14:1125.

[37] Bright T, Kuper H. A Systematic Review of Access to General Healthcare Services for People with Disabilities in Low and Middle Income Countries. International Journal of Environmental Research and Public Health. 2018;15(9).

[38] Iezzoni LI. Eliminating health and health care disparities among the growing population of people with disabilities. Health Affairs (Project Hope). 2011;30(10):1947-54.

[39] Meade MA, Mahmoudi E, Lee SY. The intersection of disability and healthcare disparities: a conceptual framework. Disability and Rehabilitation. 2015;37(7):632-41.

[40] Magnusson D, Sweeney F, Landry L. Provision of Rehabilitation Services for Children With Disabilities Living in Low- And Middle-Income Countries: A Scoping Review. Disabil Rehabil. 2019;41(7):861-8.

[41] Kuper H, Hanefeld J. Debate: can we achieve universal health coverage without a focus on disability? BMC Health Services Research. 2018;18(1):738.

[42] Tardi R, Njelesani J. Disability and the post-2015 development agenda. Disability and Rehabilitation. 2015;37(16): 1496-500.

[43] Geiger BF. Establishing a disability-inclusive agenda for sustainable development in 2015 and beyond. Global Health Promotion. 2015;22(1):64-9.

[44] Centers for Disease Control and Prevention (CDC). CDC grand rounds: public health practices to include persons with disabilities. MMWR Morbidity and Mortality Weekly Report. 2013;62(34):697-701.

[45] Lindsay S, Cagliostro E, Albarico M, Mortaji N, Karon L. A Systematic Review of the Benefits of Hiring People with Disabilities. Journal of Occupational Rehabilitation. 2018;28(4):634-55.

[46] Gewurtz RE, Langan S, Shand D. Hiring people with disabilities: A scoping review. Work (Reading, Mass). 2016; 54(1):135-48.

[47] Pineda VS, Jason Corburn, Disability, Urban Health Equity, and the Coronavirus Pandemic: Promoting Cities for All. J Urban Health. 2020 Apr 23;1-6.
[48] Iezzoni LI, Frakt AB, Pizer SD. Uninsured persons with disability confront substantial barriers to health care services. Disability and Health Journal. 2011;4(4):238-44.

[49] Hall JP, Shartzer A, Kurth NK, Thomas KC. Effect of Medicaid Expansion on Workforce Participation for People With Disabilities. American Journal of Public Health. 2017;107(2):262-4.

[50] 50] Boldrini P, Kiekens C, Bargellesi S, Brianti R, Galeri S, Lucca L, et al. First impact on services and their preparation. "Instant paper from the field" on rehabilitation answers to the Covid-19 emergency. European Journal of Physical and Rehabilitation Medicine. 2020.

[51] Choon-Huat Koh G, Hoenig H. How Should the Rehabilitation Community Prepare for 2019-nCoV? Archives of Physical Medicine and Rehabilitation. 2020.

[52] Chang MC, Park D. How should rehabilitative departments of hospitals prepare for coronavirus disease 2019? American Journal of Physical Medicine \& Rehabilitation. 2020.

[53] Zhao HM, Xie YX, Wang C. Recommendations for respiratory rehabilitation in adults with COVID-19. Chinese Medical Journal. 2020

[54] Landry MD, Tupetz A, Jalovcic D, Sheppard P, Jesus TS, Raman SR. The Novel Coronavirus (COVID-19): Making a Connection between Infectious Disease Outbreaks and Rehabilitation. Physiotherapy Canada. 2020;0(0): e20200019.

[55] Simpson R, Robinson L. Rehabilitation following critical illness in people with COVID-19 infection. American Journal of Physical Medicine \& Rehabilitation. 2020.

[56] Smith JM, Lee AC, Zeleznik H, Coffey Scott JP, Fatima A, Needham DM, et al. Home and Community-Based Physical Therapist Management of Adults With Post-Intensive Care Syndrome. Physical Therapy. 2020.

[57] Stam HJ, Stucki G, Bickenbach J. Covid-19 and Post Intensive Care Syndrome: A Call for Action. Journal of Rehabilitation Medicine. 2020.

[58] Pedersini P, Corbellini C, Villafane JH. Italian Physical Therapists' Response to the Novel COVID-19 Emergency. Physical Therapy. 2020.

[59] American Occupational Therapy Association. Telehealth in Occupational Therapy. The American journal of occupational therapy: official publication of the American Occupational Therapy Association. 2018;72(Supplement_2): 7212410059p1-p18.

[60] Tenforde AS, Hefner JE, Kodish-Wachs JE, Iaccarino MA, Paganoni S. Telehealth in Physical Medicine and Rehabilitation: A Narrative Review. PM \& R: The journal of Injury, Function, and Rehabilitation. 2017;9(5s):S51-s8.

[61] Sarfo FS, Ulasavets U, Opare-Sem OK, Ovbiagele B. TeleRehabilitation after Stroke: An Updated Systematic Review of the Literature. Journal of Stroke and Cerebrovascular Diseases: The Official Journal of National Stroke Association. 2018;27(9):2306-18.

[62] Shukla H, Nair SR, Thakker D. Role of telerehabilitation in patients following total knee arthroplasty: Evidence from a systematic literature review and meta-analysis. Journal of Telemedicine and Telecare. 2017;23(2):339-46.

[63] Laver KE, Adey-Wakeling Z, Crotty M, Lannin NA, George S, Sherrington C. Telerehabilitation services for stroke. The Cochrane Database of Systematic Reviews. 2020;1:Cd010255.

[64] Rawstorn JC, Gant N, Direito A, Beckmann C, Maddison R. Telehealth exercise-based cardiac rehabilitation: a systematic review and meta-analysis. Heart (British Cardiac Society). 2016;102(15):1183-92. 
[65] Cary MP, Jr., Spencer M, Carroll A, Hand DH, Amis K, Karan E, et al. Benefits and Challenges of Delivering Telerehabilitation Services to Rural Veterans. Home Healthcare Now. 2016;34(8):440-6.

[66] Terio M, Eriksson G, Kamwesiga JT, Guidetti S. What's in it for me? A process evaluation of the implementation of a mobile phone-supported intervention after stroke in Uganda. BMC Public Health. 2019;19(1):562.

[67] Sarfo FS, Adamu S, Awuah D, Sarfo-Kantanka O, Ovbiagele B. Potential role of tele-rehabilitation to address barriers to implementation of physical therapy among West African stroke survivors: A cross-sectional survey. Journal of the Neurological Sciences. 2017;381:203-8.

[68] Rimmer JH, Thirumalai M, Young HJ, Pekmezi D, Tracy $\mathrm{T}$, Riser E, et al. Rationale and design of the tele-exercise and multiple sclerosis (TEAMS) study: A comparative effectiveness trial between a clinic- and home-based telerehabilitation intervention for adults with multiple sclerosis (MS) living in the deep south. Contemporary Clinical Trials. 2018;71:186-93.

[69] Yan LL, Li C, Chen J, Miranda JJ, Luo R, Bettger J, et al. Prevention, management, and rehabilitation of stroke in low- and middle-income countries. eNeurologicalSci. 2016;2:21-30.

[70] Speyer R, Denman D, Wilkes-Gillan S, Chen YW, Bogaardt $\mathrm{H}$, Kim JH, et al. Effects of telehealth by allied health professionals and nurses in rural and remote areas: A systematic review and meta-analysis. Journal of Rehabilitation Medicine. 2018;50(3):225-35.

[71] American Occupational Therapy Association. A Message From AOTA on COVID-19. 2020.

[72] Armitage R, Nellums LB. COVID-19 and the consequences of isolating the elderly. The Lancet Public Health. 2020.

[73] Purssell E, Gould D, Chudleigh J. Impact of isolation on hospitalised patients who are infectious: systematic review with meta-analysis. BMJ Open. 2020;10(2):e030371.

[74] Santini ZI, Jose PE, York Cornwell E, Koyanagi A, Nielsen L, Hinrichsen C, et al. Social disconnectedness, perceived isolation, and symptoms of depression and anxiety among older Americans (NSHAP): a longitudinal mediation analysis. The Lancet Public Health. 2020;5(1):e62-e70.
[75] Newman MG, Zainal NH. The value of maintaining social connections for mental health in older people. The Lancet Public Health. 2020;5(1):e12-e3.

[76] Negrini S, Ferriero G, Kiekens C, Boldrini P. Facing in real time the challenges of the Covid-19 epidemic for rehabilitation. European Journal of Physical and Rehabilitation Medicine. 2020.

[77] Blake H, Bermingham F, Johnson G, Tabner A. Mitigating the Psychological Impact of COVID-19 on Healthcare Workers: A Digital Learning Package. International Journal of Environmental Research and Public Health. 2020;17(9).

[78] Albott CS, Wozniak JR, McGlinch BP, Wall MH, Gold BS, Vinogradov S. Battle Buddies: Rapid Deployment of a Psychological Resilience Intervention for Healthcare Workers during the COVID-19 Pandemic. Anesthesia and Analgesia. 2020.

[79] Jesus TS, Kondilis E, Filippon J, Russo G. Impact of economic recessions on healthcare workers and their crises' responses: study protocol for a systematic review of the qualitative and quantitative evidence for the development of an evidence-based conceptual framework. BMJ Open. 2019;9(11):e032972.

[80] Jesus TS, Landry MD, Dussault G, Fronteira I. Human resources for health (and rehabilitation): Six RehabWorkforce Challenges for the century. Human Resources for Health. 2017;15(1):8.

[81] Kitson A, Brook A, Harvey G, et al. Using Complexity and Network Concepts to Inform Healthcare Knowledge Translation. International Journal of Health Policy and Management 2018;7(3):231-43.

[82] 82] McDaniel RR, Jr., Lanham HJ, Anderson RA. Implications of complex adaptive systems theory for the design of research on health care organizations. Health Care Management Review. 2009;34(2):191-9.

[83] Notarnicola I, Petrucci C, De Jesus Barbosa MR, et al. Complex adaptive systems and their relevance for nursing: An evolutionary concept analysis. International Journal of Nursing Practice. 2017;23(3).

[84] Plsek PE, Greenhalgh T. Complexity science: The challenge of complexity in health care. BMJ (Clinical Research ed). 2001;323(7313):625-8. 